\title{
The Development of Expertise in the Visual Arts
}

\author{
Rebecca Chamberlain \\ Faculty of Psychology and Educational Sciences, KU Leuven, Belgium
}

\section{INTRODUCTION}

Expertise research has principally been applied to quantifiably tractable domains such as sports (e.g., Macnamara, Moreau, \& Hambrick, 2016), music (e.g., Butkovic, Ullén, \& Mosing, 2015) and chess (e.g., Gobet \& Campitelli, 2007). The quantification of expertise enables researchers to determine the similarities between different experts, which is critical for establishing the necessary and sufficient conditions for achievement within that domain. In contrast to experts in these traditional expertise domains, artists are a highly heterogeneous group of individuals, making the study of artistic expertise especially challenging. In addition, the rules of art are in a constant state of flux; in contrast to other domains of expertise (the rules of chess have remained essentially unchanged for 200 years). Some studies have used histriometric methods to deduce the correlates of artistic expertise (Damian \& Simonton, 2014) most particularly in reference to a link between artistic creativity and psychopathology (Simonton, 2014). However, this approach has limitations as information has to be gleaned retrospectively and is not collected in a controlled experimental setting.

Despite the challenges of evaluating this diverse and evolving field, a growing body of research has sought to explicate the cognitive and perceptual underpinnings of artistic expertise. Research focus has converged on observational drawing ability, which represents the most tangible artistic skill, its goal being to create a mapping between a drawn representation and the external world. Observational drawing has many of the hallmarks of a domain of expertise, as it is characterized by domain specificity (Angelone, Hass, \& Cohen, 2016), efficient processing 
(Perdreau \& Cavanagh, 2014), and enhanced visual memory (McManus et al., 2010). During the Italian Renaissance drawing was viewed as the foundation of representational art, "a seminal font from which sprang the union of theory and idea with execution" (Kenin, 1974, p.81). By contrast drawing was overlooked as a medium of expression during the twentieth century, a victim of continued post-modern attacks on traditional modes of artistic practice in favor of more conceptual approaches to art making, but the practice of drawing is beginning to resurge once again (Petherbridge, 2007).

Despite its historical primacy, drawing ability is now viewed as neither necessary nor sufficient for the kind of creative thinking that characterized artistic geniuses such as Leonardo da Vinci, Claude Monet, and Andy Warhol. However, connections between technical and creative properties of artworks have been found in past research (Kozbelt, 2004) suggesting that technical proficiency may provide a scaffold upon which creativity can thrive. In support of this, a neuroimaging study of an expert portrait artist revealed heightened activation in the frontal lobes and diminished activation in the fusiform face area (FFA) relative to control participants (Solso, 2001). This finding suggests that automated schemas created to support technical expertise free up higher-level cognitive capacities involved in creative processes. Extending this point, certain kinds of artistic training may facilitate a mode of perceiving that is conducive to discovering new ways of representing stimuli. This will be revisited in the conclusion of this chapter in an attempt to further align technical and creative skill; however, the predominant focus of this chapter will be on technical skill.

In this chapter the differences between expertise in artistic perception and production will be discussed before providing a detailed analysis of the predictors of observational drawing expertise including visual perception, visual memory, visual attention, and motor processing. 
The discussion will then move to the use of techniques and the role of practice in expertise development. This will be placed in the broader context of individual differences in personality and approaches to learning. In the conclusion these various aspects of expertise development are brought together and suggestions for future research are put forward.

\section{SIMILARITIES AND DIFFERENCES BETWEEN EXPERT ARTISTIC PERCEPTION AND PRODUCTION}

While the focus of this chapter is on expertise in artistic production, it is worth briefly outlining what is known about expertise in analyzing and appreciating artworks, an ability manifest in art curators, collectors, historians, and dealers as well as artists themselves. A great number of parallels can be drawn between abilities fostered by artistic production and those fostered by artistic perception, as highlighted by Tinio's mirror model of art (Tinio, 2013). In turn, by evaluating the differences between artistic practitioners and evaluators it will be possible to identify skills specific to each domain.

Knowledge-related processing is arguably critical in aesthetic evaluation, suggesting that expertise (consisting of domain-specific knowledge) has an impact on how art is perceived and appreciated (Leder, Belke, Oeberst, \& Augustin, 2004). Cupchik (1992) argued that functional perception is not sufficient for aesthetic experience, which demands appreciation of often ignored sensory qualities such as shapes, colors, textures, and tones. To explore the impact of artistic expertise on perception, Augustin and Leder (2006) conducted an extensive study of lay and expert responses to artworks using a natural grouping paradigm. It was found that art history students made finer-grained classifications than novices when sorting artworks, representing a more differentiated category structure. This characteristic is common in experts across domains 
of perceptual expertise (Tanaka \& Taylor, 1991) and falls in line with the proposition that expert artistic perception is facilitated by appreciation of non-denotative sensory qualities (Cupchik, 1992) and higher-order semantic properties (Leder et al., 2004). In support, it has been shown that when viewing representational artworks artists focus more on background elements and relations between objects than novices (e.g. Vogt \& Magnussen, 2007), make more global scanning eye movements (Zangemeister, Sherman, \& Stark, 1995), and make eye movements that are less driven by locally salient regions (Koide, Kubo, Nishida, Shibata, \& Ikeda, 2015), suggesting a reduction in the impact of stimulus-driven factors on artistic perception. This enhanced relational and semantic processing may also explain why art experts do not show the same preference for representational over abstract artworks as novices, as experts are able to extract higher-level aesthetic attributes from abstract images (e.g. van Paasschen, Bacci, \& Melcher, 2015). The findings of these studies largely support the notion that experts process representational and abstract artworks with less focus on functional object-based perception and more on sensory, relational, and semantic properties.

Evidence suggests that holistic processing is characteristic of perceptual expertise (e.g. Gauthier, Curran, Curby, \& Collins, 2003). However, this contrasts with empirical evidence that suggests that artistic production is associated with an enhancement of detail-focused processing and a reduction in holistic processing (Chamberlain, McManus, Riley, Rankin, \& Brunswick, 2013; Zhou et al., 2012). This suggests that expert aesthetic processing and expert artistic production might be characterized differently by their reliance upon either holistic or detailbased visual processing. In support of this Tso, Au and Hsiao (2014) explored the characteristics of expertise in Chinese character recognition and writing, which could be seen as analogous to the distinction between expert art perception and production. Holistic processing for Chinese 
characters was compared between novices, expert Chinese writers with high reading proficiency, and proficient readers who had limited experience in Chinese writing. Skilled writers perceived Chinese characters less holistically than both inexperienced writers and novices. In addition, inexperienced writers perceived characters more holistically than novices. This suggests that there is dissociation between perceptual expertise for reading and writing, with reading and writing engaging a more holistic approach and a more local approach to analysis of visual stimuli respectively. As yet, there have been no studies to examine whether such a dissociation exists for artistic expertise, therefore a comparative analysis of attentional processing in expert artists and art historians would be a valuable contribution to the literature.

\section{COGNITIVE AND PERCEPTUAL CORRELATES OF OBSERVATIONAL DRAWING EXPERTISE}

Individuals with drawing expertise outperform non-experts in a range of interacting psychological domains including: perception, attention, memory, and motor processing. The main body of research in this domain concerns experts' advantages in visual perception. The relationship between individual differences in visual perception and drawing expertise can be couched in terms of the influence of illusions and delusions (Gregory, 2003). Illusions are characterized as perceptual processes that are modular from cognition including amodal completion, gestalt grouping, and perceptual constancy. Delusions are framed as perceptual processes that interact with cognition and include visual attention, canonical visual representations, and conceptual representations (Chamberlain \& Wagemans, 2016a; although see Firestone \& Scholl, 2015, for a discussion of this issue). 


\section{Illusory Perception}

It has been proposed that individuals with drawing expertise are able to override size and shape constancy in order to access the proximal stimulus (Figure 1). This line of reasoning echoes the innocent eye theory of drawing put forward by historian John Ruskin (1856) and is supported by work with child drawing prodigies, which has shown that they take a figurative, surface focused approach to perception (Milbrath, 1998; Ruthsatz, Ruthsatz, \& Ruthsatz-Stephens, 2014). Data from perceptual constancy tasks with adult artists are, however, highly inconsistent (Cohen \& Jones, 2008; McManus, Loo, Chamberlain, Riley, \& Brunswick, 2011; Ostrofsky, Kozbelt, \& Seidel, 2012; Perdreau \& Cavanagh, 2011; Taylor \& Mitchell, 1997) and generally point to a negligible impact of illusory perception on drawing expertise (Chamberlain \& Wagemans, 2016a). Similarly, inconsistent evidence is found for a link between artistic skill and the subjective strength of visual illusions which rely on constancy cues (Chamberlain \& Wagemans, 2015; Ostrofsky, Kozbelt, \& Cohen, 2015; Schlegel et al., 2015).
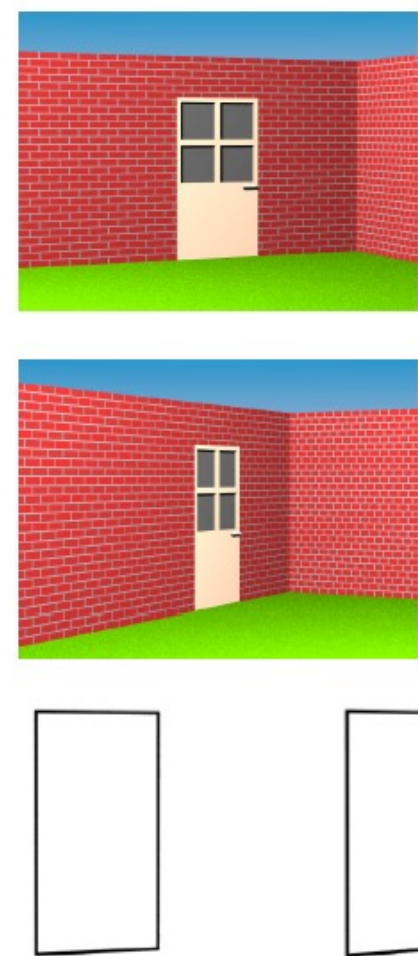
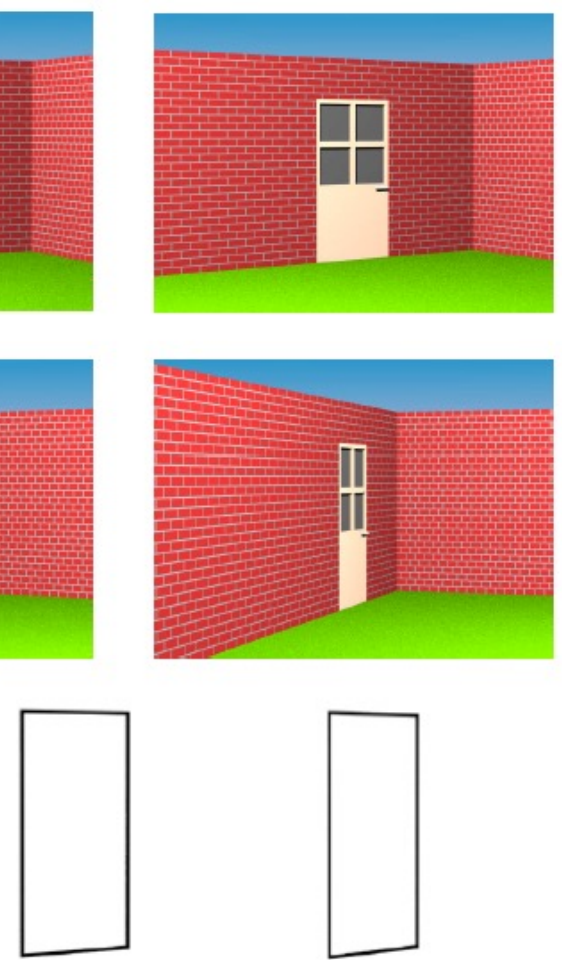

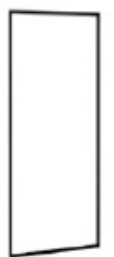

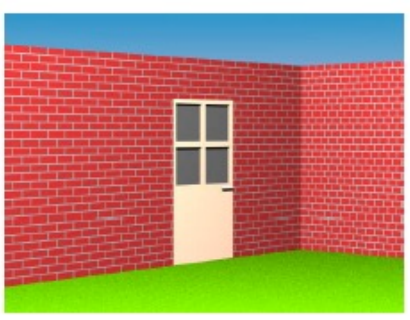
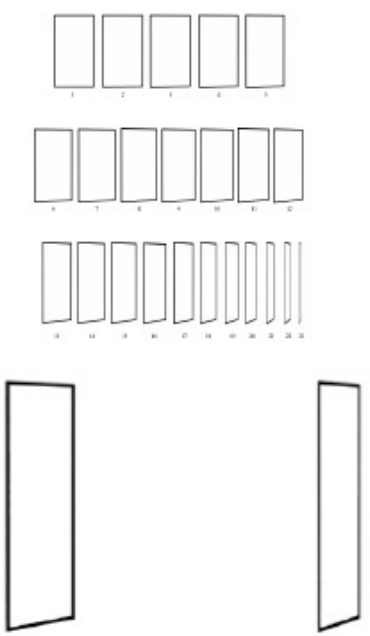
Figure 1. A task used in McManus et al. (2011) in which parallelograms are embedded in a computer-generated context (top two rows) or presented as simple shapes (bottom row) and then matched to a set of master parallelograms to test individual differences in the perception of shape constancy.

The outcome of these studies appears to be dependent on the amount of stimulus overlap between the perceptual and drawing tasks used. This is likely to be a result of the tight connection between drawings and internal, canonical representations of drawn objects (Ostrofsky, 2015). This implies that the domain of drawing is confined not to particular classes of objects or scenes, as with perceptual expertise for items such as birds and cars (Bukach, Phillips, \& Gauthier, 2010), but to the act of drawing itself.

\section{Delusory Perception}

Novice artists are often instructed to draw what they see rather than what they know, a heuristic upon which many "learn to draw" books are based. For example, a common piece of advice in instructional drawing texts is to invert the target object or scene in order to reduce familiarity with it; this makes an appearance in the seminal work Drawing on the Right Side of the Brain by Betty Edwards (Edwards, 1989). However, studies that have investigated this phenomenon have found no consistent positive impact of inverting an image on drawing accuracy (Cohen \& Earls, 2010; Kozbelt, Seidel, ElBassiouny, Mark, \& Owen, 2010; Ostrofsky, Kozbelt, Cohen, Conklin, \& Thomson, 2016). On the other hand, it has been found that expert artists render novel and familiar items similarly, whereas non-artists show large differences in approach between the two stimulus types (Glazek \& Weisberg, 2010). This suggests that the development of artistic expertise does involve an ability to see familiar objects and scenes as if they were unfamiliar in 
order to reduce the influence of biasing categorical schemas, but that image inversion is not the best route to this mode of perception.

While some classes of knowledge can provide a hindrance to accurate drawing, evidence suggests that certain classes of knowledge contribute to the development of drawing expertise. For example, non-artists frequently draw the eyes of a face too far up the head due to lack of conceptual knowledge about the structure of the human face, an error often explicitly corrected in drawing classes (Carbon \& Wirth, 2014). These internal conceptual schemas may help to guide visual attention to appropriate aspects of the target object or scene (Kozbelt \& Seeley, 2007). In support of the predictive role of top-down influences on visual attention, a robust correlation has been found between drawing expertise and enhanced local attentional processing (Chamberlain et al., 2013; Chamberlain \& Wagemans, 2015; Drake, 2013; Drake, Redash, Coleman, Haimson, \& Winner, 2010; Drake \& Winner, 2011; Pring, Ryder, Crane, \& Hermelin, 2010). These findings are based upon experimental paradigms that measure the degree to which individuals can construct global representations and can extract local detail from global form. An underlying assumption in this line of research is that individuals are characterized by a certain perceptual profile or style, with variable degrees of global and local bias. In addition to enhanced local processing, it appears that artists are able to integrate local components into global forms more easily than non-artists. In support of this Kozbelt (2001) found that artists outperformed non-artists on tasks of Gestalt completion, while a study by Perdreau and Cavanagh (2013) demonstrated that individuals with drawing expertise are better at identifying impossible figures when they are required to integrate local information across eye movements.

Enhancements of both local and global attentional processing in relation to drawing expertise appear contradictory because a common assumption is that the two modes of 
processing exist in trade-off with one another. However, recent evidence suggests that artists' enhanced performance in local and global processing tasks represents attentional flexibility rather than an attentional bias (Chamberlain \& Wagemans, 2015, 2016b). It has been proposed that artists systematically switch between proximal and distal modes of perception while creating artworks which may account for their ability to attend to holistic view-invariant properties as well as surface level detail (Lou, 2015). Here the distal mode of perception can be likened to the functional mode of perception proposed by Cupchik (1992). In sum, expert artists develop the ability to suppress negative categorical schemas and activate positive pictorial schemas through the strategic allocation of a flexible visual attentional mechanism. However, this suggests that drawing expertise does not have the hallmark of a holistic processing bias, differentiating drawing from other forms of perceptual expertise.

\section{Visual Memory}

The scope and control of visual attention are argued to be linked to visual working memory (e.g., Shipstead, Harrison, \& Engle, 2012). Given that artists show increased scope of visual attention through enhanced integration and increased control through attentional flexibility, it may be expected that expert artists possess superior visuospatial working memory as a cause or consequence of this attentional enhancement. In support, studies of children who are drawing prodigies have found evidence of enhanced visual working memory (Drake \& Winner, 2009, 2011; Ruthsatz, Ruthsatz-Stephens, \& Ruthsatz, 2014; Ruthsatz \& Urbach, 2012). Expert adult artists have been found to encode visual stimuli in central and peripheral vision more quickly and more accurately than novices (Glazek \& Weisberg, 2010). This superior encoding can be used by artists to support better visual integration ability (Perdreau \& Cavanagh, 2013). Expert artists are 
also more likely to notice masked changes to their drawings or the target object (Perdreau \& Cavanagh, 2015). However, no relationship has been found between performance on a standard change detection paradigm and representational drawing skill (Perdreau \& Cavanagh, 2015), suggesting that enhanced memory is domain-specific to the extent that it is harnessed only when drawing. While there is evidence to suggest art experts possess superior visuospatial memory, other researchers have suggested that expertise in drawing is underpinned by an ability to subvert the need for reliance on short-term memory mechanisms. In support, Cohen (2005) found that increasing the rate of gaze shifting between a drawing and the target object increased drawing accuracy in a group of novices. In addition, artists spend a substantial proportion of time blind drawing in which their eye does not leave the figure (Tchalenko, Nam, Ladanga, \& Miall, 2014). Therefore, enhanced encoding and retention is likely to play a role in drawing expertise, but there is evidence to suggest that strategies that decrease reliance on visual memory are also important.

\section{Representational Decisions}

Some of the most compelling artworks consist of only a few marks yet they communicate information about object identity and 3D form alongside more abstract qualities such as emotion and movement (Koenderink, van Doorn, \& Wagemans, 2012; Sayim \& Cavanagh, 2011). As a result, expert artists must learn to select visual features that are emotionally, dynamically, or structurally salient within an object or scene. These representational decisions interact with visual attention, as attention to appropriate aspects of a stimulus will determine which features are represented, and drawing strategies will direct visual attention toward salient features. In support of the importance of representational decisions, Kozbelt et al. (2010) and Ostrofsky et al. 
(2012) found that artists produced more accurately than novices minimal line tracings

(renderings of an object using a limited number of short pieces of tape), with artists' drawings including more features necessary for object recognition, such as junctions and occlusion barriers. This suggests that representational decisions may be driven by features for object identification, but whether these are internal object features such as the medial axis (Firestone \& Scholl, 2014) or external contour-based features such as minima of curvature (De Winter \& Wagemans, 2006) remains to be determined.

\section{Motor Processing}

A study by McManus, Ying, Fleming, Lee and Chamberlain (2014) failed to find a difference between art students and non-art students on the basis of fine motor control. However, there is evidence that motor processing does play a role in drawing expertise when considered in interplay with eye movements (Gowen \& Miall, 2006). Kozbelt (2001) reported left-over variance discriminating artists from non-artists after perceptual differences between the two had been partialled out, suggesting differences in visuomotor integration between the two groups. To test this, Glazek (2012) measured hand and eye movements in a naturalistic drawing task and found that expert artists, when drawing, were able to produce more motor output per unit of visually encoded material than novices. Tchalenko et al. (2014) formalized this by proposing that artists utilize a Gaze Shift Strategy when drawing. This is an iterative loop in which a motor program is formulated while the artist is looking at the subject and is deployed as soon as the artist moves attention back from the paper. The eye then helps to position the beginning of the line on the paper spatially while monitoring the resulting hand movement. In an fMRI study, Miall, Gowen and Tchalenko (2009) found that the act of drawing blind remains consistent with 
visually guided action, despite lack of direct visual input. That artists spend periods blind drawing suggests that complex visuomotor planning is crucial for drawing expertise. This was supported by the findings of a neuroimaging study that revealed increased gray matter density in regions of the cerebellum in expert artists (Chamberlain et al., 2014).

\section{THE ROLE OF PERSONALITY, APPROACHES TO LEARNING, AND PRACTICE}

The development of many forms of expertise involves the adoption of a range of training techniques for improving performance. The development of drawing expertise is no exception. Expert artists use tools and techniques for the amelioration of negative perceptual biases and the strengthening of positive pictorial schemas. For example, focusing on negative space is a tool for suppressing negative categorical schemas as it shifts attentional focus away from denotative properties of visual stimuli (Figure 2). On the other hand, strategies such as plotting the pivotal points on a human body and using anatomical knowledge of musculature are examples of positive pictorial schemas which artists also engage. The key role of tools and techniques for engendering flexible attention leads into a discussion of the importance of practice on the development of artistic expertise. 


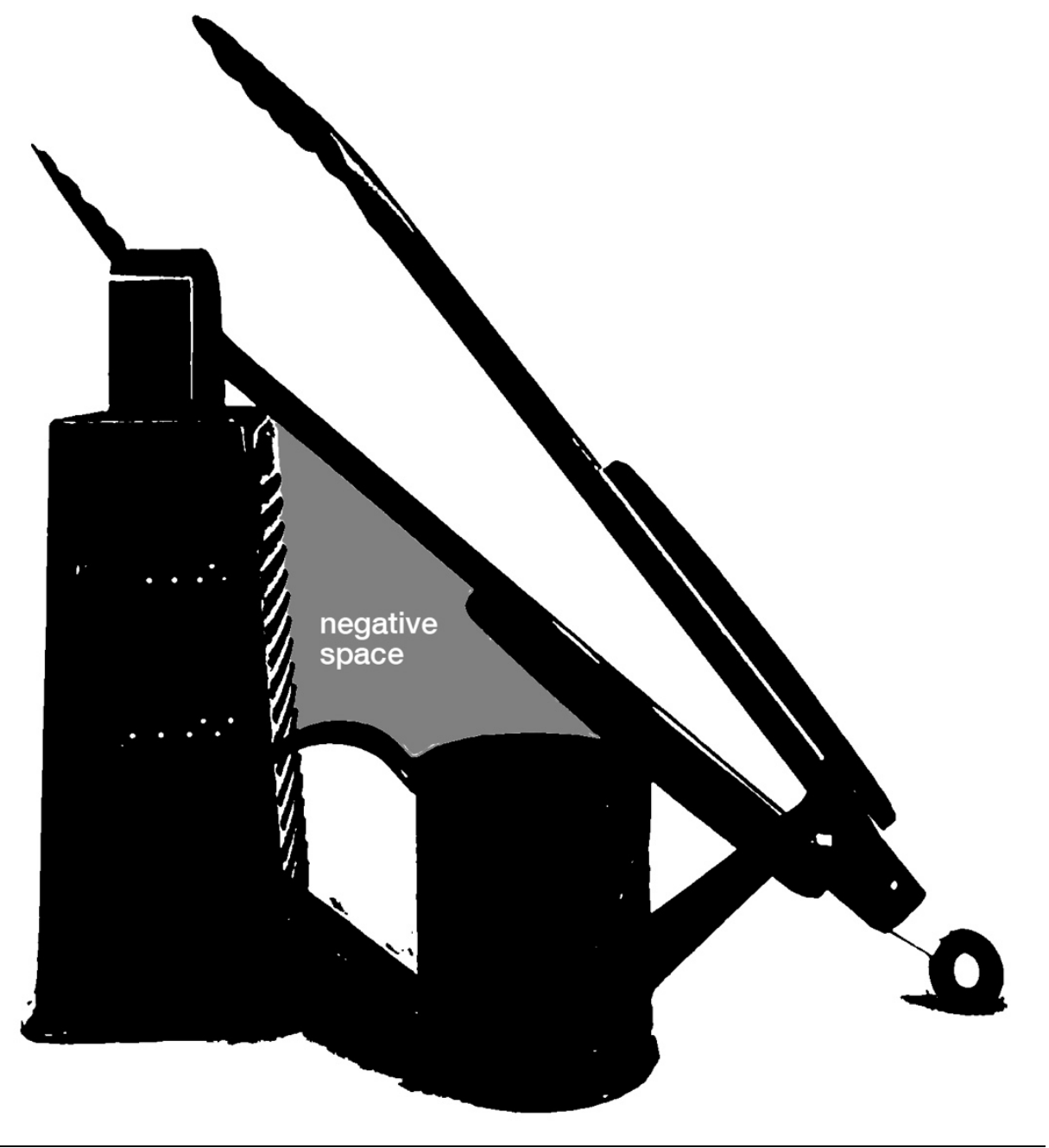

Figure 2. An array of objects with a region of negative space between the objects depicted in gray. Artists use negative space to shift attentional focus away from denotative aspects of vision and produce a more accurate drawing.

An active area of debate in the expertise literature concerns the relative roles of innate factors and experience in the acquisition of expertise (Hambrick, Altmann, et al., 2014; Hambrick, Oswald, et al., 2014; Macnamara, Hambrick, \& Oswald, 2014; Macnamara et al., 2016). Because visual art expertise research is in its infancy, there is an absence of longitudinal and crosssectional studies that could potentially pull apart the relative roles of experience and talent. Therefore, instead of reviewing existing literature of which there is very little, a recent 
correlational study is reported here that explored the role of a number of inter-related predictors that have been previously highlighted in the expertise literature: personality, approaches to learning, intelligence, and practice (for a more complete account of the findings reported here see Chamberlain, 2012; Chamberlain, McManus, Brunswick, Rankin, \& Riley, 2015). This study provides the impetus for a number of outstanding questions in this domain which are also discussed.

In the study a large cohort of art students $(N=682)$ completed questionnaires about their artistic ability, personality (Big Five Personality Scale: John, Naumann, \& Soto, 2008), and approaches to learning (Study Process Questionnaire: Fox, McManus, \& Winder, 2001). A subsample completed observational drawing tasks, the Rey-Osterrieth Complex Figure test (ROCFT) as a measure of visual memory, and Raven's Advanced Progressive Matrices as a measure of IQ $(n=301)$. The primary aim of the study was to explore whether individual differences in personality and approaches to learning predict externally-rated and self-perceived drawing ability. A secondary aim was to investigate how factors previously found to be associated with representational drawing proficiency, such as visual memory and visual imagery (McManus et al., 2010), interact with individual differences in personality and approaches to learning.

\section{Tools and Techniques for Drawing}

Art students were asked to what extent they used a range of techniques and tools for improving their drawing ability (Chamberlain, 2012). The techniques most frequently reported by art students were plotting pivotal points on the image to begin the drawing, performing quick drawings to limit the inclusion of detail, and focusing on negative space. These three strategies 
can be cast in the light of dynamic visual attention. Plotting pivotal points on the model encourages the artist to focus on global relationships between parts of the visual stimulus. Quick drawings also do this by forcing the artist to map out the global form and ignore extraneous detail. Focus on negative space encourages the artist to ignore semantic associations of local shapes in the model, again focusing on relationships between parts. More mechanical devices such as using a frame to capture part of the visual field, or a plumb line to derive vertical axes were less popular and perhaps represent a more traditional mode of expertise, but again represent ways in which artists hone their visual attention. There was strong evidence for a single underlying factor driving use of each drawing technique; if an individual used one technique then they were more likely to use others. As a whole the extent to which art students reported using these drawing techniques correlated highly with their self-perceived drawing ability and externally rated drawing ability (Chamberlain, 2012; Chamberlain et al., 2015).

\section{The Role of Practice}

Art students were asked how much time they spent drawing over the course of the last two years. This measure was positively correlated with externally rated and self-rated drawing ability (Chamberlain et al., 2015), suggesting that amount of practice is predictive of drawing ability. In order to understand the interrelations between the amount of time spent drawing, the use of techniques for drawing, and self-rated and externally-rated drawing skill, a path model was constructed and tested, producing what we termed the Drawing Backbone (Chamberlain et al., 2015). The Drawing Backbone demonstrates that the amount of time spent drawing predicts the use of more drawing techniques, which in turn predicts higher externally-rated drawing ability and self-rated drawing ability. The amount of time spent drawing and the use of more techniques 
had additional independent effects on self-rated drawing ability. Amount of time spent practicing did not independently predict drawing ability.

Having established the Drawing Backbone, a full path model was constructed including all predictive factors: personality, approaches to studying, IQ, visual memory, and drawing practice and technique (Figure 3). Surface approaches to learning related positively to time spent drawing, while an achieving (strategic) learning style positively predicted externally rated drawing ability. In addition, a surface learning style related negatively to drawing techniques and externally rated drawing ability. Several background variables exerted effects upon self-rated drawing ability, which was rated higher in males, in those with lower neuroticism $(\mathrm{N})$, higher conscientiousness (C), and with higher vividness of visual imagery (VVI). Interestingly, vividness of visual imagery was not related to externally rated drawing ability.

IQ was not included in the full path model, as it did not predict drawing expertise or any of the background variables associated with drawing, contrasting with Drake et al's (2010) study which found that non-verbal IQ predicted children's drawing ability. Research investigating the role of IQ in music and chess expertise has produced inconsistent findings (see Hambrick, Macnamara, Campitelli, Ullén, \& Mosing, 2016). However, it has been argued that well-defined domains such as music, sports and chess are likely to underplay the role of IQ in performance, whereas individual differences in creativity in the arts and sciences are more likely to reflect the influence of IQ and dispositional traits (Simonton, 2006, 2016a). It is critical to apply this model in another more creatively driven domain of art and design in order to test the claim that IQ is more predictive for creative domains than well-defined technical domains such as observational drawing. 


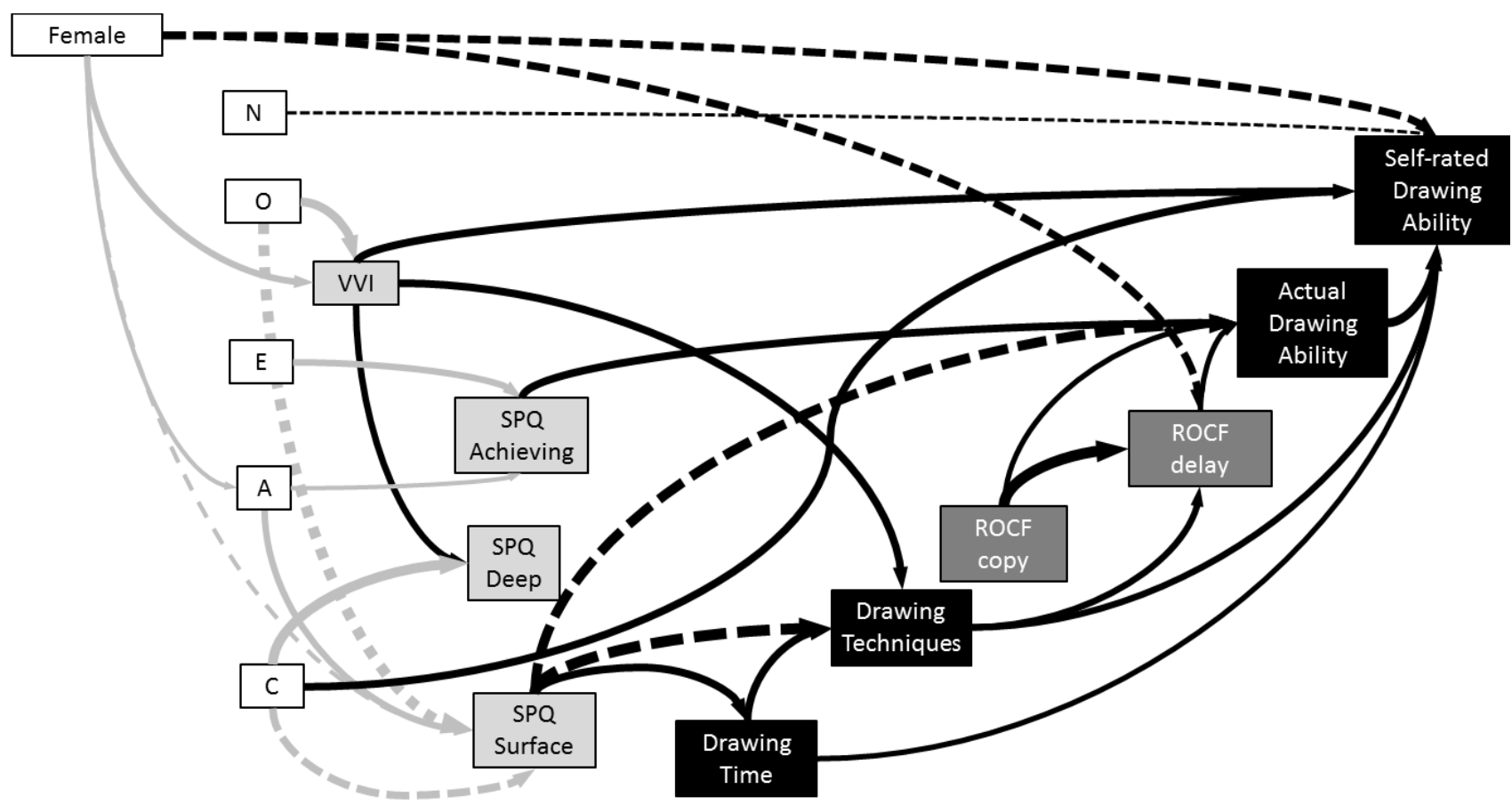

Figure 3. Full path model relating background variables to four measures of drawing and two measures of the ROCF (from Chamberlain et al., 2015). Path widths are proportional to beta coefficients. Paths with positive beta coefficients are drawn as solid lines and those with negative beta coefficients as dashed lines.

\section{Practice Doesn't Always Make Perfect}

The full path model generated from this data is one in which actual drawing expertise is primarily caused by learning more drawing techniques, and having more drawing techniques is largely caused by more time spent drawing. This suggests that a large amount of practice alone is not sufficient for the development of expertise, unless the practice is associated with a flexible approach to technique usage. This conclusion is supported by the association between lower levels of actual drawing ability, higher levels of practice, and lower levels of technique use in surface learners in the full path model. The uptake of strategies for practice, rather than cumulative time spent practicing, has been shown to be a prominent predicting factor in expertise 
development in the domains of music (Hallam, 2001) and chess (Campitelli \& Gobet, 2011), and artistic expertise is no exception.

Reported levels of practice and technique usage appeared to artificially inflate participants' self-rated drawing ability. In part, this false inflation of the role of practice may be due to the popularization of the theory of deliberate practice (Ericsson, Krampe, \& Tesch-Romer, 1993) and a consequent emphasis on the amount of time spent practicing for expertise acquisition, which has been challenged (e.g. Gobet \& Campetelli, 2007). In support, it has been found that retrospective reports of amount of time practicing, rather than keeping a log of practice activities, lead to larger effect sizes in terms of the contribution of deliberate practice (Hambrick et al., 2016; Macnamara et al., 2014). These data suggest that the degree to which students can effectively assess their ability and what contributes to it may also play a role in the development of expertise and should be a focus of investigation.

The development of expertise in observational drawing is underpinned by individual differences in approaches to learning, which are themselves driven by differences in personality. A surface strategy, while increasing the amount of time an individual spends practicing, discourages the novice from learning a range of techniques for expertise acquisition and results in a lower level of overall ability. An achieving strategy to learning by contrast, predicted by extroversion and agreeableness, proves the most successful for expertise development in this domain. This approach to learning involves an intention to succeed and motivation to achieve the best educational outcome, by organization of time and the learning environment (Diseth, 2002). As such it reflects an individual's ability to process the learning context and respond to task demands. This makes intuitive sense when we consider that in order to develop representational drawing expertise the sheer amount of time spent drawing is not as relevant as the strategic 
adoption of successful strategies for producing a convincing likeness. A strategic learning style may also be tangentially related to the concept of grit or assertiveness that has previously been found to be prevalent in eminent creators (Duckworth, Peterson, Matthews, \& Kelly, 2007; Simonton, 2016b), although this assertion has yet to be tested. On the other hand, deep approaches to learning, although not implicated in the current model, may be predictive of more creative aspects of artistic practice because this learning style reflects the desire to relate ideas to one another (Diseth, 2002). It is therefore important that this model be tested in relation to other art activities with more or less creative input in order to assess its generalizability.

The Big Five personality factors were only indirectly predictive of drawing expertise, with their impact being mediated by approaches to learning, amount of time spent practicing and the uptake of techniques. Those most heavily implicated were extroversion and agreeableness, which related positively to a strategic approach to learning. In addition, conscientiousness was negatively related to surface approaches to learning, but conscientiousness was a positive predictor of a deep approach to learning, which was not associated with higher levels of practice or expertise. Drake and Winner (in Chapter 15, Why Deliberate Practice Is Not Enough: Evidence of Talent in Drawing) find higher levels of agreeableness in drawing prodigies which may be related to the enhanced experience of flow found in those with a "rage to master" (Winner, 1997). Contrary to expectation, openness to experience was not implicated in the development of drawing expertise, even though artistic individuals have been found to exhibit higher openness to experience (Burch, Pavelis, Hemsley, \& Corr, 2006), and openness to experience predicts engagement in the visual arts (Chamorro-Premuzic, Reimers, Hsu, \& Ahmetoglu, 2009). The lack of direct links from personality to expertise (which can be seen in the larger correlational matrix in Chamberlain et al., 2015) reflects the findings of a number of expertise studies showing 
that deliberate practice mediates the effects of personality on expertise (Hambrick et al., 2016). However, a study showing a direct link between emotional control and chess performance does suggest that there may be some aspects of personality that directly predict expertise, independently of the individuals' dispositional characteristics (Grabner, Stern, \& Neubauer, 2007), and a wide variety of personality variables should be included in future cross-sectional studies.

Cognitive abilities such as visual memory appear to predict performance largely independently of other dispositional predictive factors in the current model. However, it is not possible from a correlational design to determine whether skills such as visual memory drive individuals toward development of expertise, or are themselves a product of engagement in artistic activities. Future longitudinal designs will be able to address the direction of causation between perceptual and cognitive abilities and artistic expertise. Furthermore, it is unclear whether amount of drawing practice and techniques for drawing directly predict expert performance or whether they are both underpinned by genetic factors, as has been found to be the case for musical ability (Mosing, Madison, Pedersen, Kuja-Halkola, \& Ullén, 2014). Future studies investigating dispositional, practice, and talent-based predictors of artistic expertise should utilize genetic paradigms such as twin studies alongside longitudinal causal methodologies to address these gaps in our current understanding.

\section{CONCLUSIONS AND SUGGESTIONS FOR FURTHER RESEARCH}

The study of artistic expertise is challenging relative to other expertise domains, but this challenge is not insurmountable. The body of research reviewed here represents substantial leaps in recent years in methodology and theoretical understanding, by developing reliable and valid 
means for assessing artistic experience and performance and testing them against established paradigms in perceptual and cognitive domains. That being said, the study of subjective qualities of artworks such as pictorial accuracy and creativity still requires much more research focus. In addition, the relatively narrow scope of current research on observational drawing should be broadened by studying subdomains such as abstract painting, photography, sculpture, and conceptual art. Even within the domain of drawing, distinctions in practice can be drawn and are a valid focus of research. Investigating the impact of training in perceptual drawing, which focuses on surface qualities (Edwards, 1989), in comparison with design drawing which focuses on visualization (McKim, 1972), will shed light upon how engagement in different aspects of art and design facilitates different strands of perceptual expertise. Carving up the larger domain of artistic expertise therefore will be valuable and is foreseeable as the field develops.

Another way of delineating the basis of artistic expertise is to investigate the distinction between expert perception for art evaluation in contrast to perception for art production. It has been shown that the two domains have commonalities as they both engender a mode of perception that is inconsistent with functional perception for everyday purposes (Cupchik, 1992). However, they also differ in the sense that perception for aesthetic evaluation appears to favor a holistic attentional attitude, whereas artistic production appears to favor a more flexible attentional attitude. To confirm this interpretation of the existing data it is necessary to conduct cross-sectional analyses of different kinds of art professionals such as art historians in comparison with fine artists. Artistic production can also be contrasted with perceptual expertise from other domains (for cars, birds, etc.), but this too is yet to be investigated empirically. It may be possible to investigate subpopulations of artists with different perceptual expertise (for example, portrait and landscape painters) in order to assess the domain-specificity of perceptual 
enhancements. However, at this point it can be concluded that in the case of most artists the domain of expertise is the act of art making and is intimately connected with motor processes rather than with particular classes of visual stimuli.

Substantial progress has been made in determining the perceptual and cognitive underpinnings of observational drawing expertise, as an exemplar of artistic expertise. Upon review of the available evidence it would appear that enhancement of the scope and control of visual attention is critically implicated in the development of drawing expertise, while bottom-up perceptual processing appears to be relatively unaffected by level of expertise (Chamberlain \& Wagemans, 2016a). Visual attention in turn may also account for related abilities that are found to be enhanced in visual artists such as visuospatial working memory, representational decisions, and visuomotor integration. In addition, it can be proposed that top-down attentional mechanisms that enable the artist to attend to overlooked visual features could facilitate higher forms of artistic production and appreciation. Robust representational schemas could free up cognitive resources for creative processing (Solso, 2001). If these two proposals hold, one can foresee a link between technical artistic skill, artistic appreciation, and creative output. Technical artistic skill under this framework engenders a flexible and efficient perceptual system, which enables the artist to access multiple interpretations in the work of others and multiple meanings in incoming sensory and conceptual information to facilitate creative thinking.

It can be proposed that expert artists develop increased scope and control of visual attention through the use of diverse techniques for drawing that enable them to mitigate the effects of negative biases on perception and engage positive pictorial schemas. In support of this a recent study indicated that drawing expertise is developed as a result of practice that is focused not on the amount of time artists spent engaged in drawing, but in the diversity of techniques 
they use to develop their practice (Chamberlain et al., 2015). The adoption of techniques is driven by individual differences in personality and approaches to studying, suggesting a complex interaction of innate and learned abilities and character traits in the determination of expertise. Interestingly the only background variable that interacted with a cognitive skill (visual memory) in the aforementioned study was the uptake of drawing techniques. This suggests that there are two relatively independent routes to development of expertise in the visual arts: one through heightened cognitive and perceptual skills, and the other through motivation to learn for strategic purposes. The uptake of a diverse range of drawing techniques serves to bridge these two routes to expertise. The next logical step for research in this domain is to investigate which particular techniques lead to the development of which kinds of skills. In addition, future research should engage with work with child prodigies who demonstrate a "rage to master," in order to investigate how innate skills and traits interact with learned elements of expertise development (see Chapter 15). Research that identifies those skills that can and cannot be successfully trained in the context of artistic expertise will undoubtedly have broad implications for art and design education. 


\section{REFERENCES}

Angelone, B. L., Hass, R. W., \& Cohen, M. (2016). Skill transfer in visual arts expertise. Psychology of Aesthetics, Creativity, and the Arts, 10(2), 147-156. http://doi.org/10.1037/aca0000053

Augustin, D., \& Leder, H. (2006). Art expertise: A study of concepts and conceptual spaces. Psychology Science, 48(2), 135.

Bukach, Phillips, W. S., \& Gauthier, I. (2010). Limits of generalization between categories and implications for theories of category specificity. Attention, Perception \& Psychophysics, 72(7), 1865-1874. http://doi.org/10.3758/APP.72.7.1865

Burch, G. S. J., Pavelis, C., Hemsley, D. R., \& Corr, P. J. (2006). Schizotypy and creativity in visual artists. British Journal of Psychology, 97(2), 177-190. http://doi.org/10.1348/000712605X60030

Butkovic, A., Ullén, F., \& Mosing, M. A. (2015). Personality related traits as predictors of music practice: Underlying environmental and genetic influences. Personality and Individual Differences, 74, 133-138. http://doi.org/10.1016/j.paid.2014.10.006

Campitelli, G., \& Gobet, F. (2011). Deliberate Practice: Necessary But Not Sufficient. Current Directions in Psychological Science, 20(5), 280-285. http://doi.org/10.1177/0963721411421922

Carbon, C.-C., \& Wirth, B. E. (2014). Neanderthal paintings? Production of prototypical human (Homo sapiens) faces shows systematic distortions. Perception, 43(1), 99-102. http://doi.org/10.1068/p7604

Chamberlain, R. (2012). Attitudes and Approaches to Observational Drawing in Contemporary Artistic Practice Attitudes and Approaches to Observational Drawing in Contemporary Artistic Practice. Drawing Knowledge. TRACEY Drawing and Visualisation Research. Retrieved from http://www.lboro.ac.uk/microsites/sota/tracey/journal/edu/old/images/Articles/Rebecca Chamberlain-TRACEY-Journal-DK-2012.docx

Chamberlain, R., McManus, C., Brunswick, N., Rankin, Q., \& Riley, H. (2015). Scratching the Surface: Practice, Personality, Approaches to Learning, and the Acquisition of HighLevel Representational Drawing Ability. Psychology of Aesthetics, Creativity, and the Arts. http://doi.org/10.1037/aca0000011

Chamberlain, R., McManus, I. C., Brunswick, N., Rankin, Q., Riley, H., \& Kanai, R. (2014). Drawing on the right side of the brain: A voxel-based morphometry analysis of observational drawing. NeuroImage, 96, 167-173. http://doi.org/10.1016/j.neuroimage.2014.03.062

Chamberlain, R., McManus, I. C., Riley, H., Rankin, Q., \& Brunswick, N. (2013). Local processing enhancements associated with superior observational drawing are due to enhanced perceptual functioning, not weak central coherence. The Quarterly Journal of Experimental Psychology, 66(7), 1448-1466. http://doi.org/10.1080/17470218.2012.750678

Chamberlain, R., \& Wagemans, J. (2015). Visual arts training is linked to flexible attention to local and global levels of visual stimuli. Acta Psychologica, 161, 185-197.

Chamberlain, R., \& Wagemans, J. (2016a). The genesis of errors in drawing. Neuroscience \& Biobehavioral Reviews, 65, 195-207. http://doi.org/10.1016/j.neubiorev.2016.04.002 
Chamberlain, R., \& Wagemans, J. (2016b). Visual and cognitive flexibility in artists. Presented at the Meeting of the Vision Science Society (VSS), St Pete Beach, FL.

Chamorro-Premuzic, T., Reimers, S., Hsu, A., \& Ahmetoglu, G. (2009). Who art thou?

Personality predictors of artistic preferences in a large UK sample: The importance of openness. British Journal of Psychology, 100(3), 501-516. http://doi.org/10.1348/000712608X366867

Cohen, D. J. (2005). Look little, look often: The influence of gaze frequency on drawing accuracy. Perception \& Psychophysics, 67(6), 997-1009.

Cohen, D. J., \& Earls, H. (2010). Inverting an image does not improve drawing accuracy. Psychology of Aesthetics, Creativity, and the Arts, 4(3), 168-172. http://doi.org/10.1037/a0017054

Cohen, D. J., \& Jones, H. E. (2008). How shape constancy relates to drawing accuracy. Psychology of Aesthetics, Creativity, and the Arts, 2(1), 8-19. http://doi.org/10.1037/1931-3896.2.1.8

Cupchik, G. C. (1992). From perception to production: A multilevel analysis of the aesthetic process. In Emerging Visions of the Aesthetic Process: Psychology, Semiology, and Philosophy (pp. 83-99). Cambridge University Press.

Damian, R., \& Simonton, D. K. (2014). Diversifying experiences in the development of genius and their impact on creative cognition. In The Wiley handbook of genius (pp. 375-393). John Wiley \& Sons, Inc.

De Winter, J., \& Wagemans, J. (2006). Segmentation of object outlines into parts: A large-scale integrative study. Cognition, 99(3), 275-325. http://doi.org/10.1016/j.cognition.2005.03.004

Diseth, A. (2002). The Relationship between Intelligence, Approaches to Learning and Academic Achievement. Scandinavian Journal of Educational Research, 46(2), 219-230. http://doi.org/10.1080/00313830220142218

Drake, J. E. (2013). Is superior local processing in the visuospatial domain a function of drawing talent rather than autism spectrum disorder? Psychology of Aesthetics, Creativity, and the Arts, 7(2), 203-209. http://doi.org/10.1037/a0030636

Drake, J. E., Redash, A., Coleman, K., Haimson, J., \& Winner, E. (2010). “Autistic” Local Processing Bias also Found in Children Gifted in Realistic Drawing. Journal of Autism and Developmental Disorders, 40(6), 762-773. http://doi.org/10.1007/s10803-009-09230

Drake, J. E., \& Winner, E. (2009). Precocious realists: Perceptual and cognitive characteristics associated with drawing talent in non-autistic children. Philosophical Transactions of the Royal Society B: Biological Sciences, 364(1522), 1449-1458. http://doi.org/10.1098/rstb.2008.0295

Drake, J. E., \& Winner, E. (2011). Realistic Drawing Talent in Typical Adults is Associated with the Same Kind of Local Processing Bias Found in Individuals with ASD. Journal of Autism and Developmental Disorders, 41(9), 1192-1201. http://doi.org/10.1007/s10803010-1143-3

Duckworth, A. L., Peterson, C., Matthews, M. D., \& Kelly, D. R. (2007). Grit: Perseverance and passion for long-term goals. Journal of Personality and Social Psychology, 92(6), 10871101. http://doi.org/10.1037/0022-3514.92.6.1087

Edwards, B. (1989). Drawing on the right side of the brain. New York: Putnam. 
Ericsson, K. A., Krampe, R., \& Tesch-Romer, C. (1993). The role of deliberate practice in the acquisition of expert performance. Psychological Review, 100, 363-406.

Firestone, C., \& Scholl, B. J. (2014). "Please tap the shape, anywhere you like": Shape skeletons in human vision revealed by an exceedingly simple measure. Psychological Science, 25(2), 377-386.

Firestone, C., \& Scholl, B. J. (2015). Cognition does not affect perception: Evaluating the evidence for "top-down"effects. Behavioral and Brain Sciences, 1-72.

Fox, R. A., McManus, I. C., \& Winder, B. C. (2001). The shortened Study Process Questionnaire: An investigation of its structure and longitudinal stability using confirmatory factor analysis. British Journal of Educational Psychology, 71(4), 511-530.

Gauthier, I., Curran, T., Curby, K. M., \& Collins, D. (2003). Perceptual interference supports a non-modular account of face processing. Nature Neuroscience, 6(4), 428-432.

Glazek, K. (2012). Visual and motor processing in visual artists: Implications for cognitive and neural mechanisms. Psychology of Aesthetics, Creativity, and the Arts, 6(2), 155-167. http://doi.org/10.1037/a0025184

Glazek, K. J., \& Weisberg, R. W. (2010). Expertise in Visual Art is Associated with Altered Perceptual Strategies Within and Across Domains: Evidence from Eye Tracking. In Proceedings of the 32nd Annual Conference of the Cognitive Science Society (pp. 417422). Retrieved from http://csjarchive.cogsci.rpi.edu/proceedings/2010/papers/0070/paper0070.pdf

Gobet, F., \& Campitelli, G. (2007). The role of domain-specific practice, handedness, and starting age in chess. Developmental Psychology, 43(1), 159-172. http://doi.org/10.1037/0012-1649.43.1.159

Gowen, E., \& Miall, R. C. (2006). Eye-hand interactions in tracing and drawing tasks. Human Movement Science, 25(4-5), 568-585. http://doi.org/10.1016/j.humov.2006.06.005

Grabner, R. H., Stern, E., \& Neubauer, A. C. (2007). Individual differences in chess expertise: A psychometric investigation. Acta Psychologica, 124(3), 398-420. http://doi.org/10.1016/j.actpsy.2006.07.008

Gregory, R. L. (2003). Delusions. Perception, 32(3), 257-261. http://doi.org/10.1068/p3203ed

Hallam, S. (2001). The Development of Expertise in Young Musicians: Strategy Use, Knowledge Acquisition and Individual Diversity. Music Education Research, 3(1), 7-23. http://doi.org/10.1080/14613800020029914

Hambrick, D. Z., Altmann, E. M., Oswald, F. L., Meinz, E. J., Gobet, F., \& Campitelli, G. (2014). Accounting for expert performance: The devil is in the details. Intelligence, 45 , 112-114. http://doi.org/10.1016/j.intell.2014.01.007

Hambrick, D. Z., Macnamara, B. N., Campitelli, G., Ullén, F., \& Mosing, M. A. (2016). Beyond Born versus Made. In Psychology of Learning and Motivation (Vol. 64, pp. 1-55). Elsevier. Retrieved from http://linkinghub.elsevier.com/retrieve/pii/S0079742115000328

Hambrick, D. Z., Oswald, F. L., Altmann, E. M., Meinz, E. J., Gobet, F., \& Campitelli, G. (2014). Deliberate practice: Is that all it takes to become an expert? Intelligence, 45, 3445. http://doi.org/10.1016/j.intell.2013.04.001

John, O., Naumann, L. P., \& Soto, C. J. (2008). Paradigm shift to the integrative big five trait taxonomy: History, Measurement, and Conceptual Issues. In Handbook of personality: Theory and research (pp. 114-158). New York: Guilford Press.

Kenin, R. (1974). The art of drawing: from the dawn of history to the era of the Impressionists. New York: Paddington Press. 
Koenderink, J., van Doorn, A., \& Wagemans, J. (2012). Picasso in the mind's eye of the beholder: Three-dimensional filling-in of ambiguous line drawings. Cognition, 125(3), 394-412. http://doi.org/10.1016/j.cognition.2012.07.019

Koide, N., Kubo, T., Nishida, S., Shibata, T., \& Ikeda, K. (2015). Art Expertise Reduces Influence of Visual Salience on Fixation in Viewing Abstract-Paintings. PLOS ONE, 10(2), e0117696. http://doi.org/10.1371/journal.pone.0117696

Kozbelt, A. (2001). Artists as experts in visual cognition. Visual Cognition, 8(6), 705-723. http://doi.org/10.1080/13506280042000090

Kozbelt, A. (2004). Originality and technical skill as components of artistic quality. Empirical Studies of the Arts, 22(2), 157-170.

Kozbelt, A., \& Seeley, W. P. (2007). Integrating art historical, psychological, and neuroscientific explanations of artists' advantages in drawing and perception. Psychology of Aesthetics, Creativity, and the Arts, 1(2), 80-90. http://doi.org/10.1037/1931-3896.1.2.80

Kozbelt, A., Seidel, A., ElBassiouny, A., Mark, Y., \& Owen, D. R. (2010). Visual selection contributes to artists' advantages in realistic drawing. Psychology of Aesthetics, Creativity, and the Arts, 4(2), 93-102. http://doi.org/10.1037/a0017657

Leder, H., Belke, B., Oeberst, A., \& Augustin, D. (2004). A model of aesthetic appreciation and aesthetic judgments. British Journal of Psychology, 95(4), 489-508.

Lou, L. (2015). Observational visual depiction involves interplays of proximal and distal modes of seeing. Presented at the Visual Science of Art Conference, Liverpool, UK.

Macnamara, B. N., Hambrick, D. Z., \& Oswald, F. L. (2014). Deliberate Practice and Performance in Music, Games, Sports, Education, and Professions: A Meta-Analysis. Psychological Science, 25(8), 1608-1618. http://doi.org/10.1177/0956797614535810

Macnamara, B. N., Moreau, D., \& Hambrick, D. Z. (2016). The Relationship Between Deliberate Practice and Performance in Sports A Meta-Analysis. Perspectives on Psychological Science, 11(3), 333-350.

McKim, R. (1972). Experiences in visual thinking. Belmont, CA: Brooks/Cole Publishing Company.

McManus, I. C., Chamberlain, R., Loo, P.-W., Rankin, Q., Riley, H., \& Brunswick, N. (2010). Art students who cannot draw: Exploring the relations between drawing ability, visual memory, accuracy of copying, and dyslexia. Psychology of Aesthetics, Creativity, and the Arts, 4(1), 18-30. http://doi.org/10.1037/a0017335

McManus, I. C., Loo, P.-W., Chamberlain, R., Riley, H., \& Brunswick, N. (2011). Does shape constancy relate to drawing ability? Two failures to replicate. Empirical Studies of the Arts, 29(2), 191-208.

McManus, I. C., Ying, B. T. Z., Fleming, E., Lee, P., \& Chamberlain, R. (2014). Testing Ruskin: seeing, drawing and remembering complex curves. Presented at the Visual Science of Art Conference, Belgrade, Serbia.

Miall, R. C., Gowen, E., \& Tchalenko, J. (2009). Drawing cartoon faces - a functional imaging study of the cognitive neuroscience of drawing. Cortex, 45(3), 394-406. http://doi.org/10.1016/j.cortex.2007.10.013

Milbrath, C. (1998). Patterns of artistic development in children: Comparative studies of talent. New York: Cambridge University Press.

Mosing, M. A., Madison, G., Pedersen, N. L., Kuja-Halkola, R., \& Ullén, F. (2014). Practice does not make perfect: No causal effect of music practice on music ability. Psychological Science, 956797614541990. 
Ostrofsky, J. (2015). Developmental and Geographic Analyses of Spatial Biases in Face Drawings Produced by Children. Empirical Studies of the Arts, 33(1), 3-17. http://doi.org/10.1177/0276237415569978

Ostrofsky, J., Kozbelt, A., \& Cohen, D. J. (2015). Observational drawing biases are predicted by biases in perception: Empirical support of the misperception hypothesis of drawing accuracy with respect to two angle illusions. The Quarterly Journal of Experimental Psychology, 68(5), 1007-1025. http://doi.org/10.1080/17470218.2014.973889

Ostrofsky, J., Kozbelt, A., \& Seidel, A. (2012). Perceptual constancies and visual selection as predictors of realistic drawing skill. Psychology of Aesthetics, Creativity, and the Arts, 6(2), 124-136. http://doi.org/10.1037/a0026384

Ostrofsky, J., Kozbelt, A., Cohen, D. J., Conklin, L., \& Thomson, K. (2016). Face Inversion Impairs the Ability to Draw Long-Range, but Not Short-Range, Spatial Relationships Between Features. Empirical Studies of the Arts, 34(2), 221-233. http://doi.org/10.1177/0276237416634851

Perdreau, F., \& Cavanagh, P. (2011). Do Artists See Their Retinas? Frontiers in Human Neuroscience, 5. http://doi.org/10.3389/fnhum.2011.00171

Perdreau, F., \& Cavanagh, P. (2013). The artist's advantage: Better integration of object information across eye movements. I-Perception, 4(6), 380-395. http://doi.org/10.1068/i0574

Perdreau, F., \& Cavanagh, P. (2014). Drawing skill is related to the efficiency of encoding object structure. I-Perception, 5(2), 101-119. http://doi.org/10.1068/i0635

Perdreau, F., \& Cavanagh, P. (2015). Drawing experts have better visual memory while drawing. Journal of Vision, 15(5), 5. http://doi.org/10.1167/15.5.5

Petherbridge, D. (2007). On the moving line and the future subjunctive of drawing in a postDuchampian age. Futures, 39(10), 1191-1200. http://doi.org/10.1016/j.futures.2007.05.004

Pring, L., Ryder, N., Crane, L., \& Hermelin, B. (2010). Local and global processing in savant artists with autism. Perception, 39(8), 1094-1103. http://doi.org/10.1068/p6674

Ruskin, J. (1856). The elements of drawing. Mineola, NY: Dover Publications Inc.

Ruthsatz, J., Ruthsatz, K., \& Ruthsatz-Stephens, K. (2014). Putting practice into perspective: Child prodigies as evidence of innate talent. Intelligence, 45, 60-65. http://doi.org/10.1016/j.intell.2013.08.003

Ruthsatz, J., Ruthsatz-Stephens, K., \& Ruthsatz, K. (2014). The cognitive bases of exceptional abilities in child prodigies by domain: Similarities and differences. Intelligence, 44, 11 14. http://doi.org/10.1016/j.intell.2014.01.010

Ruthsatz, J., \& Urbach, J. B. (2012). Child prodigy: A novel cognitive profile places elevated general intelligence, exceptional working memory and attention to detail at the root of prodigiousness. Intelligence, 40(5), 419-426. http://doi.org/10.1016/j.intell.2012.06.002

Sayim, B., \& Cavanagh, P. (2011). What Line Drawings Reveal About the Visual Brain. Frontiers in Human Neuroscience, 5. http://doi.org/10.3389/fnhum.2011.00118

Schlegel, A., Alexander, P., Fogelson, S. V., Li, X., Lu, Z., Kohler, P. J., ... Meng, M. (2015). The artist emerges: Visual art learning alters neural structure and function. NeuroImage, 105, 440-451. http://doi.org/10.1016/j.neuroimage.2014.11.014

Shipstead, Z., Harrison, T. L., \& Engle, R. W. (2012). Working memory capacity and visual attention: Top-down and bottom-up guidance. The Quarterly Journal of Experimental Psychology, 65(3), 401-407. http://doi.org/10.1080/17470218.2012.655698 
Simonton, D. K. (2006). Presidential IQ, Openness, Intellectual Brilliance, and Leadership: Estimates and Correlations for 42 U.S. Chief Executives. Political Psychology, 27(4), 511-526.

Simonton, D. K. (2014). More method in the mad-genius controversy: A historiometric study of 204 historic creators. Psychology of Aesthetics, Creativity, and the Arts, 8(1), 53-61. http://doi.org/10.1037/a0035367

Simonton, D. K. (2016a). Intelligence, inheritance, motivation and expertise: Review of "Grit: The power of passion and perserverance" A. Duckworth and "Peak: Secrets from the new science of expertise" A. Ericsson and R. Pool. Intelligence, 58. http://doi.org/10.1016/j.intell.2016.05.005

Simonton, D. K. (2016b). Reverse engineering genius: historiometric studies of superlative talent: Reverse engineering genius. Annals of the New York Academy of Sciences. http://doi.org/10.1111/nyas. 13054

Solso, R. L. (2001). Brain activities in a skilled versus a novice artist: An fMRI study. Leonardo, $34(1), 31-34$.

Tanaka, J. W., \& Taylor, M. (1991). Object categories and expertise: Is the basic level in the eye of the beholder. Cognitive Psychology, 23, 457-482.

Taylor, L. M., \& Mitchell, P. (1997). Judgments of apparent shape contaminated by knowledge of reality: Viewing circles obliquely. British Journal of Psychology, 88(4), 653-670.

Tchalenko, J., Nam, S.-H., Ladanga, M., \& Miall, R. C. (2014). The gaze-shift strategy in drawing. Psychology of Aesthetics, Creativity, and the Arts, 8(3), 330-339. http://doi.org/10.1037/a0036132

Tinio, P. P. L. (2013). From artistic creation to aesthetic reception: The mirror model of art. Psychology of Aesthetics, Creativity, and the Arts, 7(3), 265-275. http://doi.org/10.1037/a0030872

Tso, R. V.-y., Au, T. K.-f., \& Hsiao, J. H.-w. (2014). Perceptual Expertise: Can Sensorimotor Experience Change Holistic Processing and Left-Side Bias? Psychological Science, 25(9), 1757-1767. http://doi.org/10.1177/0956797614541284

van Paasschen, J., Bacci, F., \& Melcher, D. P. (2015). The Influence of Art Expertise and Training on Emotion and Preference Ratings for Representational and Abstract Artworks. PLOS ONE, 10(8), e0134241. http://doi.org/10.1371/journal.pone.0134241

Vogt, S., \& Magnussen, S. (2007). Expertise in pictorial perception: Eye-movement patterns and visual memory in artists and laymen. Perception, 36(1), 91-100. http://doi.org/10.1068/p5262

Winner, E. (1997) Gifted Children: Myths and Realities. New York, NY: Basic Books

Zangemeister, W. H., Sherman, K., \& Stark, L. (1995). Evidence for a global scanpath strategy in viewing abstract compared with realistic images. Neuropsychologia, 33(8), 10091025.

Zhou, G., Cheng, Z., Zhang, X., \& Wong, A. C.-N. (2012). Smaller holistic processing of faces associated with face drawing experience. Psychonomic Bulletin \& Review, 19(2), 157162. http://doi.org/10.3758/s13423-011-0174-x 